\title{
Sampling frequency trade-offs in the assessment of mean transit times of tropical montane catchment waters under semi-steady-state conditions
}

\author{
E. Timbe ${ }^{1,2}$, D. Windhorst ${ }^{2}$, R. Celleri ${ }^{1,3}$, L. Timbe ${ }^{1,4}$, P. Crespo ${ }^{1,3}$, H.-G. Frede ${ }^{2}$, J. Feyen ${ }^{1}$, and L. Breuer ${ }^{2}$ \\ ${ }^{1}$ Departamento de Recursos Hídricos y Ciencias Ambientales, Universidad de Cuenca, Cuenca, Ecuador \\ ${ }^{2}$ Institute for Landscape Ecology and Resources Management (ILR), Research Centre for Bio Systems, Land Use and \\ Nutrition (IFZ), Justus-Liebig-Universität Gießen, Gießen, Germany \\ ${ }^{3}$ Facultad de Ciencias Agropecuarias, Universidad de Cuenca, Cuenca, Ecuador \\ ${ }^{4}$ Facultad de Ciencias Químicas, Universidad de Cuenca, Cuenca, Ecuador
}

Correspondence to: E. Timbe (edison_timbe@yahoo.com)

Received: 17 October 2014 - Published in Hydrol. Earth Syst. Sci. Discuss.: 7 November 2014

Revised: 23 January 2015 - Accepted: 9 February 2015 - Published: 2 March 2015

\begin{abstract}
Precipitation event samples and weekly based water samples from streams and soils were collected in a tropical montane cloud forest catchment for 2 years and analyzed for stable water isotopes in order to understand the effect of sampling frequency in the performance of three lumped-parameter distribution functions (exponential-piston flow, linear-piston flow and gamma) which were used to estimate mean transit times of waters. Precipitation data, used as input function for the models, were aggregated to daily, weekly, bi-weekly, monthly and bi-monthly sampling resolutions, while analyzed frequencies for outflows went from weekly to bi-monthly. By using different scenarios involving diverse sampling frequencies, this study reveals that the effect of lowering the sampling frequency depends on the water type. For soil waters, with transit times on the order of few weeks, there was a clear trend of over predictions. In contrast, the trend for stream waters, which have a more damped isotopic signal and mean transit times on the order of 2 to 4 years, was less clear and showed a dependence on the type of model used. The trade-off to coarse data resolutions could potentially lead to misleading conclusions on how water actually moves through the catchment, notwithstanding that these predictions could reach better fitting efficiencies, fewer uncertainties, errors and biases. For both water types an optimal sampling frequency seems to be 1 or at most 2 weeks. The results of our analyses provide information for
\end{abstract}

the planning of future fieldwork in similar Andean or other catchments.

\section{Introduction}

In catchment hydrology, the application of environmental isotopes as tracers, and particularly stable water isotopes, was enhanced by the contributions of Maloszewski and $\mathrm{Zu}$ ber (1982, 1993), who described and applied the methodology of tracer dating in detail. In their approach the routing of water in a catchment was mathematically expressed by a lumped-parameter transit time distribution function (TTD). In this method, fundamental conditions are the homogeneity of the system and steady-state conditions. Although presently more complex models are being tested (e.g., models dealing with time-variable conditions: Rinaldo et al., 2011; Botter et al., 2010, 2011), the lumpedmodel approaches are still widely used since they provide basic inferences of the water paths and the transit times of water (e.g., Muñoz-Villers and McDonnell, 2012; Hrachowitz et al., 2009; Kabeya et al., 2006; Maloszewski et al., 2006; McGuire and McDonnell, 2006; Rodgers et al., 2005; McGuire et al., 2002; Soulsby et al., 2000; Dewalle et al., 1997; Timbe et al., 2014). 
The insights on TTDs and mean transit times (MTTs) of streams, springs, groundwater or even soil waters to be gained by the joint application of lumped-parameter models and tracers also can serve as a starting point towards employing an improved sampling campaign which integrates more sources of data or other types of tracers (e.g., Kirchner et al., 2010; Stewart et al., 2010), not to mention a more accurate sampling length and frequency. Along with the increase of their applicability, the handling and processing of tracer data, and even the estimation of uncertainties of the inferred results, is becoming a routine process in hydrologic research (e.g., McGuire and McDonnell, 2006). Solutions, formerly based only on the best fit to a particular model, now frequently include a range of behavioral or possible solutions (Weiler et al., 2003; Vaché and McDonnell, 2006; McGuire et al., 2007; Hrachowitz et al., 2009, 2010, 2013; Birkel et al., 2011; Capell et al., 2012; Muñoz-Villers and McDonnell, 2012; Timbe et al., 2014). However, an appropriate sensitivity analysis of the model parameters to factors such as the degree of temporal resolution of the input data used to calibrate tracer-based lumped models is still uncommon as it is in traditional rainfall-runoff modeling (McGuire and McDonnell, 2006).

Such an analysis is necessary; the predictions provided by steady-state approaches are simple approximations of the real functioning of a catchment system, although only valid in waters in which time-invariant conditions are applicable (e.g., groundwater systems). Besides, most steady-state analyses of published studies are based on relatively poor information in terms of temporal and spatial variability of environmental tracers (Rinaldo et al., 2011). For instance, by using a conceptual lumped model, Birkel et al. (2010) found that isotope data of high temporal resolution were beneficial for model conceptualization and calibration. That assertion was corroborated by Hrachowitz et al. (2011) who, using a lumped-parameter model, found evidence of potential misleading insights when low sampling resolution data were used. The sampling frequency should be in accordance to the expected timescale of the transit or residence time of the analyzed waters (McGuire and McDonnell, 2006). However, in practice, this factor is constrained by logistical reasons, especially in remote catchments.

Most tracer studies looking for the TTD or MTT of a catchment are based on weekly, bi-weekly, and less common on monthly data. Rare are samplings at higher timescales than weekly (e.g., Kirchner et al., 2000; Birkel et al., 2010). Sometimes high temporal resolution measurements are used for the analysis of rainfall-runoff events at smaller spatial scales, e.g., hillslope, in which the transit time of fast flows on the order of hours to few days is being searched for. But for those cases, time-variant rather than steady-state approaches are necessary (e.g., Heidbüchel et al., 2012; Rinaldo et al., 2011; Botter et al., 2011; Weiler et al., 2003; Barnes and Bonell, 1996). In general, the temporal resolution of the data employed to infer hydrological process under- standing from lumped-parameter models can influence the results, thereby making it difficult to compare predictions from different studies (Hrachowitz et al., 2011).

To gain insights from the effect of the sampling frequency on the results of lumped-parameter models, we collected time series of stable water isotopes in a baseflow-dominated Ecuadorian tropical montane cloud forest catchment. Data were aggregated into diverse levels of temporal resolution in order to analyze their effect on the predictions from three widely known lumped models, whose applicability was identified in previous research (Timbe et al., 2014). The temporal resolution of this study consists of around 2 years of highresolution samples of rainfall events, weekly grab samples of stream waters from the main river and its seven tributaries, and bulk water samples from six representative soils sites. For the analyzed waters, only baseflow or steady-state conditions were considered.

The hypotheses on which this study is based are (1) for the analyzed waters, some temporal resolutions of input data could substantially influence the results of lumped-parameter models; in this regard (2) a sensitivity analysis of the sampling resolution is essential as part of analyzing the suitability of a lumped-parameter model, similarities or divergences of results from diverse sampling trade-offs could provide insights on the degree of reliability of a particular sampling frequency.

\section{Materials and methods}

\subsection{Study area}

The study area of the San Francisco River catchment $\left(76.9 \mathrm{~km}^{2}\right.$, Fig. 1) is located in the eastern escarpments of the Andean mountains in southern Ecuador. The local tropical climate is mainly influenced by easterly trade winds and thus by the Atlantic circulation patterns (Beck et al., 2008). The mean annual temperature ranges from $15^{\circ} \mathrm{C}$ in the lower part of the catchment to $10^{\circ} \mathrm{C}$ on the ridges. Annual precipitation ranges from 2500 to $4000 \mathrm{~mm}$ in wet years. Rainfall intensities are low (less than $10 \mathrm{~mm} \mathrm{~h}^{-1}$ ) and the relative humidity is high, up to $96 \%$ at the ridges. The topography of the area has an altitudinal range of 1725 to $3250 \mathrm{~m}$ a.s.l. and is characterized by steep valleys with an average slope of $63 \%$. Seven main tributaries feed the San Francisco River, their catchment areas vary in size from 0.7 to $34.9 \mathrm{~km}^{2}$ and in their land cover, constituted mainly by pristine forest and pastures (Goettlicher et al., 2009). According Timbe et al. (2014), who used weekly isotope data, MTT of water in the surficial horizons is on the order of few weeks to months. The stream waters of the river and its tributaries are perennial and baseflow dominated. Previous research accounted the groundwater contribution in $85 \%$ of the total runoff, characterized by MTTs on the order of 2 to 4 years (Timbe et al., 2014; Crespo et al., 2012). A detailed description of the physical, hydro- 


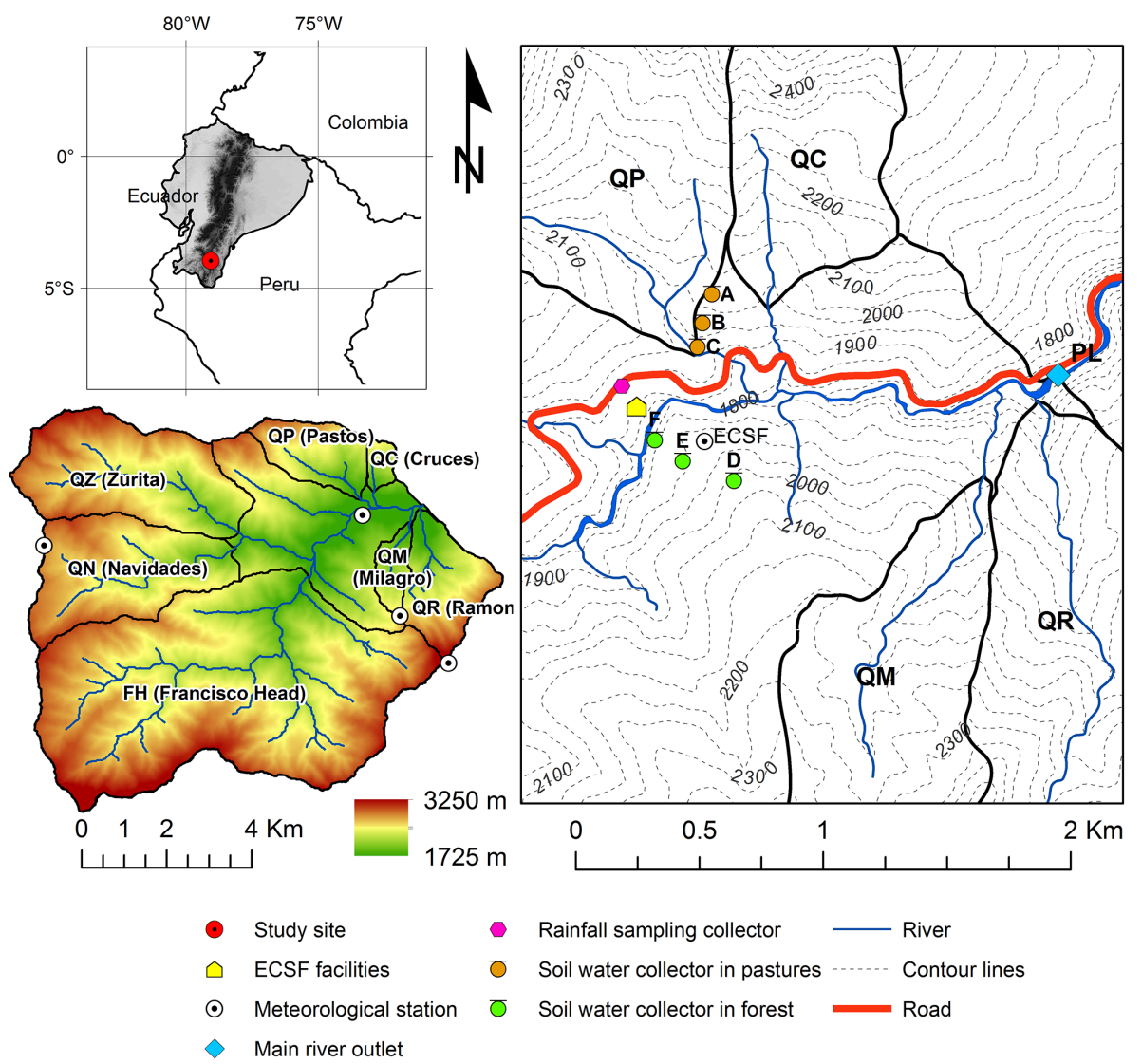

Figure 1. San Francisco catchment with sampling locations and delineation of corresponding drainage area. Names and acronyms are shown in bold. Framed image shows the zoomed area of the lower part of the catchment.

logical and land cover characteristics of the catchment and main tributaries are given in Timbe et al. (2014), whereas additional information on the climate and ecosystem gradients of the research area can be found in Bendix et al. (2008), Fiedler and Beck (2008) and Wilcke et al. (2008).

\subsection{Sampling site selection and methodology}

For the present study, the same field data used in Timbe et al. (2014) was employed. In brief, for around 2 years and starting in mid-August 2010, samples for isotopic analyses $\left(\delta^{18} \mathrm{O}\right.$ and $\left.\delta^{2} \mathrm{H}\right)$ were collected in the study catchment. Weekly based dip samples were taken for stream waters at every sub-catchment and main catchment outlets while volume-weighted samples for soil waters were collected using wick samplers located in soil sites covered with pastures and forest (Fig. 1). As stream water samples represent an instantaneous condition in time, in order to account for the baseflow conditions of the catchment, samples taken during extreme rainfall-runoff events were discarded. Rainfall samples for isotopic analyses were taken after every rainfall event, in the lower part of the catchment at $1900 \mathrm{~m}$ a.s.l. The end of every event of rainfall was marked by a time span of at least $30 \mathrm{~min}$ without rainfall. The isotopic vari- ation of rainfall through the catchment was inferred from the sampled point by using the altitudinal isotopic gradient of $-0.22 \% \circ \delta^{18} \mathrm{O},-1.12 \% \circ \delta^{2} \mathrm{H}$ and $0.6 \%$ deuterium excess per $100 \mathrm{~m}$ elevation gain, as estimated by Windhorst et al. (2013) for the same investigated area. In this study only $\delta^{18} \mathrm{O}$ was selected for further analysis since $\delta^{18} \mathrm{O}$ and $\delta^{2} \mathrm{H}$ showed a high linear correlation. The stable isotope signatures are reported in per mil value relative to the Vienna Standard Mean Ocean Water (VSMOW) (Craig, 1961). The water isotopic composition was analyzed by wavelength-scanned cavity ring down spectroscopy (WS-CRDS) with a precision of $0.1 \%$ for $\delta^{18} \mathrm{O}$ and $0.5 \%$ for $\delta^{2} \mathrm{H}$ (PicarroL1102-i, CA, USA).

It should be noticed that while the aim of Timbe el al. (2014) was to identify the most reliable TTDs and to characterize the MTTs for all the sampled sites (i.e., a total of 32 sites covering waters from streams, soils and springs) based on the intercomparison of fitting efficiencies and ranges of uncertainties provided by predictions of seven lumped-parameter models, for the present research we focused on accounting the average trends of predictions as a result of using diverse sampling frequencies. In Timbe et al. (2014) a fixed weekly sampling frequency was used. To 
avoid overrepresentation of a specific isotopic signal in the depiction of general predictive trends, the number of analyzed stream waters was limited to the seven main nested sub-catchments: Navidades (QN), Pastos (QP), Cruces (QC), Milagro (QM), Ramon (QR), Francisco Head (FH), Zurita (QZ) and the main catchment outlet Planta (PL) (Fig. 1). Accordingly, only lumped models were considered. Since differences between soil water sampling sites were bigger than on-site differences (Timbe et al., 2014) in this study we limited the number of soil depths from three to one specific soil depth, more precisely at $0.25 \mathrm{~m}$, resulting in a total of six sampling locations (A, B, C, D, E, F) instead of 18 as performed in Timbe et al. (2014). In the latter research water samples were collected at three depths, respective at 0.10 , 0.25 and $0.40 \mathrm{~m}$ below surface.

Besides selecting only representative sampling locations, also a slight variance in the length of the data set characterizes both studies. In the present study rainfall and stream waters were analyzed for the period of the 1 October 2010 to mid-August 2012, while in Timbe et al. (2014) the used data set stretched from mid-August 2010 to mid-August 2012. The decision to shorten the time series by shifting the beginning of the study period to the last quarter of 2010 was taken in order to homogenize the different time series for the aggregation into different sampling frequencies (up to 3 months during tryouts) and to assure that divergences among predictions are only due to the applied temporal resolutions. An additional reason for shortening the time series is that the wick samplers for the collection of soil water samples were installed after October 2010 (Timbe et al., 2014).

\subsection{Lumped-parameter equation and distribution functions to infer transit times of water}

For the calculation of the MTT, the lumped-parameter approach was utilized. This method considers the aquifer system as an integral unit, while the flow pattern is assumed to be constant. Particular for conservative tracers, the transport of a tracer through a catchment can be mathematically expressed by the convolution integral equation for stable tracers (Eq. 1), in which the tracer's outflow composition $C_{\text {out }}$ at a time $t$ (time of exit) consists of the tracer's input composition $C_{\text {in }}$ that falls uniformly on the catchment in a previous time step $t^{\prime}$ (time of entry). $C_{\text {out }}$ is lagged according to a TTD that rules the tracer's transit time $(\tau)$. This TTD is represented by the normalized distribution function of the tracer $g(\tau)$ injected instantaneously over an entire area.

$C_{\text {out }}(t)=\int_{0}^{\infty} C_{\mathrm{in}}(t-\tau) g(\tau) \mathrm{d} \tau$

Based on findings from a previous research (Timbe et al., 2014), for the stream waters of San Francisco, the exponential-piston (EPM) and gamma (GM) models were identified as reliable TTDs in terms of providing predictions with high fitting efficiencies and low uncertainty ranges; while the linear-piston (LPM) model and GM were found most appropriate for soil water data (a detailed description of the TTD models is shown in Timbe et al., 2014). These models are widely known among the two-parameter TTD models (Kirchner et al., 2000, 2001; Maloszewski and Zuber, 1982; McGuire and McDonnell, 2006; Amin and Campana, 1996). EPM and LPM are defined by $\tau$ and $\eta$ ( $\eta$ explains the portion of contribution of each type of flow), while the GM is defined by the shape $\alpha$ and scale $\beta$ parameters.

\subsection{Model performance}

The convolution method for the calibration of every model, describing each sampled water and sampling frequency, was used. Input data for models consisted of isotopic time series of rainfall, while the observed variation of each analyzed effluent (e.g., stream or soil waters) were used for calibration. The used approach follows nearly the same methodology applied in Timbe et al. (2014), with some slight modifications to allow the analysis of diverse sampling resolutions. Briefly, the goodness of fit of every simulation, as defined by the Nash-Sutcliffe efficiency coefficient (NSE) (Nash and Sutcliffe, 1970), was calculated. To automate and standardize the equation's resolution, we repeated 10000 simulations by randomly sampling, using the Monte Carlo based Generalized Likelihood Uncertainty Estimation (GLUE) (Beven and Freer, 2001) method. Behavioral solutions, for which weighted quantiles between 0.05 and 0.95 (90\% of the behavioral limits) were calculated, were selected for every prediction based on a lower limit $(5 \%)$ which were dependent on the best NSE reached for every case. From these values, in order to ease intercomparisons, the magnitude of uncertainty for each predicted parameter was calculated by subtracting the lower behavioral limit from the maximum one $(\Delta \tau, \Delta \alpha$, $\Delta \eta)$. For the best predictions, the root mean square error (RMSE) and the bias with respect to the mean (BIAS) were calculated to account for errors and deviations of predictions. In both cases they were reported in $\%$ units.

In most simulations, the convergence of solutions towards one solution peak was clearly defined within a predefined fixed range dependent on the type of model: $\tau$ [0-10 years], $\alpha$ [0.01-10], $\eta$ [1-10]. For cases with more than one solution peak, in order to improve the convergence of $\tau$, we restricted the behavioral solutions to the largest peak for the second model parameter (assumption made by the authors). It should also be noticed that for the particular case of LPM, in order to easy the interpretation of results and at the same time improve the convergence of $\tau$, the lower limit value for $\eta$ was set to 1 instead of 0.5 as it was in Timbe et al. (2014). The latter consideration was performed after accounting the results from the referred study in which for most of the analyzed soil water sites the best solutions provided by an LPM were characterized by a $\eta$ slightly larger than 1 . 
Similarly to Timbe et al. (2014) and other related studies (Hrachowitz et al., 2011; Muñoz-Villers and McDonnell, 2012) an artificial warm-up period was generated by repeating measured isotopic rainfall time series in a loop. For our case, to guarantee stable results, the warming-up period was set to 20 times the length of the observed time series.

\subsection{Temporal resolution of data}

Solving the convolution method requires a fixed time step for the input function $C_{\text {in }}$, which in turn will be the same time step resolution of the predicted output data $C_{\text {out }}$. In order to check the effect of the temporal resolution of sampling on the predictions, the simulations were performed by aggregating high-resolution samples of rainfall (i.e., per event) into five levels of temporal resolution: daily, weekly, bi-weekly, monthly and bi-monthly. For each data set, the isotopic composition for every event was weighted according to the collected volume for the considered time span. For time spans corresponding to zero rainfall, the isotope signal of the antecedent time step was used. By using a predefined TTD function $g(\tau)$, Eq. (1) could be solved and it became possible to derive the best possible fit to the observed data for every outflow by varying the model parameters. Depending on how we aggregated the data, two distinct scenarios were considered.

Scenario 1: for every sampled site, observed isotopic data series of rainfall and outflows were aggregated into coarser levels of data resolution. Since the finest resolution of outflow waters was weekly, we used this data resolution to calibrate models having daily rainfall data sets as input. For weekly, bi-weekly, monthly and bi-monthly data sets, we used the corresponding time step resolution. For stream water, due to the smooth variation between two successive isotopic data, no volumetric weighting was applied, but a simple averaging of weekly isotopic values. For soil water, volumetric weighting was applied.

Scenario 2: diminishing the sampling resolution in both types of observed data at the same time (rainfall and outflows), as performed in Scenarios 1, could lead to incomplete insights if we consider that coarse data resolutions, such as monthly or bi-monthly, could provide fewer uncertainties or better simulation statistics than finer data resolutions (by the simple fact that less data are involved in the analyses). In this regard, a second scenario was set up, in which only the highest temporal resolution data of observed outflows (i.e., weekly) was considered for calibration; while the rainfall data were considered the same as in Scenario 1. Results from this second scenario facilitate to discern the adequacy of a particular time resolution over another.

It should be noted that, given these considerations, the predictive results for daily and weekly time resolutions are the same for both scenarios. For data resolutions larger than weekly, the combination of two different levels of information in the same lumped-predictive model (e.g., monthly data for the input function of rainfall and weekly for the observed outflows) was handled through considering weekly time steps, although previously those rainfall values were derived as volumetrically weighted rainfall data from biweekly, monthly or bi-monthly sampling resolutions.

Analysis of these two scenarios provides a quantifiable effect of data resolution on parameter estimation of the applied models. For comparative purposes among sampling tradeoffs, the finest analyzed temporal resolution (i.e., daily rainfall and weekly outflow data) was considered as the main reference in order to define a particular result as a lower or higher estimate. In order to look for similarities, divergences and trends between predictions, results were visually compared using box-and-whisker plots and the respective median (expressed in this text with a tilde on the top of a parameter symbol, e.g., $\widetilde{\tau}$ ) for the grouped six soil water sites and the eight stream water sites. Interpretation of the physical meaning of results considers that the MTT of water can be adequately characterized by $\tau$.

\section{Results}

For this study, as a result of the use of a slightly shorter time series than those used in Timbe et al. (2014), slight differences for model-parameter predictions can be found when weekly based predictions are compared to the former published results.

\subsection{Soil water (Table 1, Fig. 2)}

\subsubsection{Type 1 scenarios - varying resolution of rain and soil water isotope data}

Median values of NSE for GM and LPM were rather similar, ranging between 0.76 and 0.86 . Likewise, for both models the RMSE and BIAS were comparable between time resolutions. Furthermore, best predictions of $\tau$, as defined by the NSE, showed a clear increasing trend of this parameter versus a decreasing temporal sampling resolution. For GM the median value of $\tau$ between sampled sites (i.e., $\tilde{\tau}$ ) for the daily sampling resolution was 4.66 weeks, while for weekly and bi-weekly resolutions data this value slightly rose to 5.15 and 5.89 weeks. Considering coarser data resolutions, as monthly or bi-monthly, $\tau$ even went up to 6.62 and 8.99 weeks. The values and the corresponding trend for LPM were similar to the one obtained using GM. For LPM $\widetilde{\tau}$ varied from 4.59 to 8.87 weeks using the finest and the coarsest time resolutions, respectively. In general, GLUE-based uncertainties for $\tau$ estimations, as defined by median values $(\widehat{\Delta \tau})$, were lower using daily rather than coarser sampling resolutions. In this regard, larger differences were found for LPM ranging from 1.44 weeks using daily data to 3.47 weeks using bi-monthly data; while for GM the range of uncertainty varied from 1.83 to 2.06 weeks. 
Table 1. Soil water simulation results using gamma and linear-piston models considering scenarios 1 and 2.

\begin{tabular}{|c|c|c|c|c|c|c|c|c|c|c|c|c|c|c|c|c|c|}
\hline $\mathrm{P}$ & $\mathrm{Sc}$ & $\mathrm{Sf}_{\mathrm{R}}$ & $\mathrm{Sf}_{\mathrm{S}}$ & $\mathrm{A}_{\mathrm{GM}}$ & $\mathrm{B}_{\mathrm{GM}}$ & $\mathrm{C}_{\mathrm{GM}}$ & $\mathrm{D}_{\mathrm{GM}}$ & $\mathrm{E}_{\mathrm{GM}}$ & $\mathrm{F}_{\mathrm{GM}}$ & $\widetilde{X}_{\mathrm{GM}}$ & $A_{L P M}$ & $\mathrm{~B}_{\mathrm{LPM}}$ & $\mathrm{C}_{\mathrm{LPM}}$ & $\mathrm{D}_{\mathrm{LPM}}$ & $\mathrm{E}_{\mathrm{LPM}}$ & $F_{L P M}$ & $\tilde{X}_{\mathrm{LPM}}$ \\
\hline \multirow{8}{*}{$\begin{array}{l}\frac{\bar{v}}{d} \\
\frac{d}{3} \\
N\end{array}$} & $1 \& 2$ & $\mathrm{D}$ & W & 4.82 & 4.50 & 3.42 & 6.93 & 6.74 & 4.44 & 4.66 & 4.58 & 4.61 & 3.23 & 5.99 & 6.14 & 4.36 & 4.59 \\
\hline & $1 \& 2$ & W & W & 5.33 & 4.97 & 3.75 & 7.48 & 7.02 & 4.67 & 5.15 & 5.69 & 4.53 & 3.79 & 6.29 & 6.11 & 4.49 & 5.11 \\
\hline & 1 & $\mathrm{Bw}$ & $\mathrm{Bw}$ & 6.01 & 5.41 & 4.56 & 8.43 & 8.26 & 5.77 & 5.89 & 5.96 & 5.18 & 4.27 & 7.71 & 7.34 & 5.92 & 5.94 \\
\hline & 2 & $\mathrm{Bw}$ & W & 5.50 & 4.99 & 3.88 & 7.67 & 7.21 & 4.81 & 5.25 & 5.80 & 4.88 & 3.64 & 6.88 & 6.89 & 4.81 & 5.34 \\
\hline & 1 & $\mathrm{M}$ & $\mathrm{M}$ & 7.27 & 5.79 & 4.98 & 9.30 & 9.75 & 5.97 & 6.62 & 7.17 & 7.69 & 4.19 & 8.31 & 9.17 & 6.18 & 7.43 \\
\hline & 2 & M & W & 5.57 & 5.01 & 3.95 & 7.75 & 7.24 & 4.49 & 5.29 & 5.77 & 4.72 & 3.86 & 6.73 & 6.88 & 4.46 & 5.25 \\
\hline & 1 & $\mathrm{Bm}$ & $\mathrm{Bm}$ & 9.68 & 8.22 & 7.55 & 9.74 & 10.58 & 8.29 & 8.99 & 11.02 & 8.87 & 8.87 & 8.75 & 8.17 & 11.60 & 8.87 \\
\hline & 2 & $\mathrm{Bm}$ & W & 5.38 & 4.16 & 2.69 & 6.46 & 6.37 & 4.63 & 5.00 & 4.99 & 3.92 & 2.83 & 5.62 & 6.17 & 4.37 & 4.68 \\
\hline \multirow{8}{*}{\begin{tabular}{l}
$\frac{\bar{v}}{\tilde{d}}$ \\
$\frac{3}{3}$ \\
\multirow{4}{\Delta}{}
\end{tabular}} & $1 \& 2$ & $\mathrm{D}$ & $\mathrm{W}$ & 2.05 & 1.62 & 1.68 & 2.03 & 1.58 & 1.98 & 1.83 & 1.64 & 1.43 & 1.67 & 1.12 & 1.25 & 1.44 & 1.44 \\
\hline & $1 \& 2$ & W & W & 2.08 & 1.92 & 1.69 & 2.17 & 1.95 & 1.89 & 1.93 & 1.75 & 1.27 & 1.52 & 1.43 & 1.52 & 1.75 & 1.52 \\
\hline & 1 & $\mathrm{Bw}$ & $\mathrm{Bw}$ & 1.84 & 2.16 & 1.75 & 2.39 & 2.27 & 2.06 & 2.11 & 1.55 & 2.22 & 2.00 & 1.04 & 0.93 & 1.77 & 1.66 \\
\hline & 2 & $\mathrm{Bw}$ & W & 2.11 & 2.04 & 1.79 & 2.07 & 2.07 & 1.97 & 2.06 & 1.45 & 1.35 & 1.61 & 1.00 & 1.31 & 1.73 & 1.40 \\
\hline & 1 & M & $\mathrm{M}$ & 1.62 & 1.93 & 1.49 & 2.40 & 2.55 & 1.82 & 1.87 & 1.60 & 1.48 & 3.07 & 1.59 & 1.65 & 1.43 & 1.60 \\
\hline & 2 & M & W & 1.87 & 1.91 & 1.77 & 2.52 & 2.05 & 1.81 & 1.89 & 1.53 & 1.66 & 1.81 & 0.89 & 1.41 & 1.74 & 1.60 \\
\hline & 1 & $\mathrm{Bm}$ & $\mathrm{Bm}$ & 1.87 & 2.41 & 1.95 & 2.17 & 2.44 & 1.67 & 2.06 & 3.49 & 3.73 & 3.53 & 3.31 & 3.45 & 3.34 & 3.47 \\
\hline & 2 & $\mathrm{Bm}$ & W & 1.74 & 2.30 & 1.93 & 2.20 & 1.84 & 1.80 & 1.89 & 1.35 & 1.72 & 2.04 & 1.60 & 1.79 & 1.28 & 1.66 \\
\hline \multirow{8}{*}{$\begin{array}{l}\text { I } \\
\text { I } \\
\text { t } \\
\text { ठ }\end{array}$} & $1 \& 2$ & $\mathrm{D}$ & W & 1.51 & 1.76 & 1.59 & 2.11 & 3.64 & 2.66 & 1.94 & 1.02 & 1.01 & 1.02 & 1.00 & 1.07 & 1.17 & 1.02 \\
\hline & $1 \& 2$ & W & W & 1.64 & 1.72 & 1.71 & 2.04 & 2.76 & 2.21 & 1.88 & 1.07 & 1.01 & 1.07 & 1.03 & 1.00 & 1.03 & 1.03 \\
\hline & 1 & Bw & $\mathrm{Bw}$ & 1.85 & 1.97 & 3.11 & 1.93 & 2.37 & 1.78 & 1.95 & 1.01 & 1.03 & 1.02 & 1.08 & 1.02 & 1.19 & 1.03 \\
\hline & 2 & $\mathrm{Bw}$ & $\mathrm{W}$ & 1.70 & 1.61 & 1.53 & 1.76 & 2.32 & 1.83 & 1.73 & 1.08 & 1.08 & 1.02 & 1.05 & 1.06 & 1.08 & 1.07 \\
\hline & 1 & $\mathrm{M}$ & $\mathrm{M}$ & 3.91 & 4.75 & 5.06 & 2.73 & 2.32 & 3.55 & 3.73 & 1.16 & 1.22 & 1.00 & 1.01 & 1.12 & 1.02 & 1.07 \\
\hline & 2 & M & W & 1.85 & 2.38 & 2.26 & 1.87 & 2.31 & 2.19 & 2.23 & 1.06 & 1.04 & 1.08 & 1.00 & 1.06 & 1.02 & 1.05 \\
\hline & 1 & $\mathrm{Bm}$ & $\mathrm{Bm}$ & 4.50 & 4.86 & 6.19 & 4.58 & 3.94 & 4.52 & 4.55 & 1.40 & 1.15 & 1.12 & 1.08 & 1.03 & 1.51 & 1.14 \\
\hline & 2 & $\mathrm{Bm}$ & W & 2.31 & 1.42 & 1.37 & 1.91 & 3.71 & 1.65 & 1.78 & 1.07 & 1.03 & 1.17 & 1.03 & 1.26 & 1.04 & 1.06 \\
\hline \multirow{8}{*}{$\begin{array}{l}\frac{T}{I} \\
\check{\jmath} \\
\vec{\Delta} \\
\partial \\
\dot{\triangleleft}\end{array}$} & $1 \& 2$ & D & W & 2.83 & 3.02 & 2.95 & 2.70 & 5.64 & 6.72 & 2.99 & 0.17 & 0.36 & 0.37 & 0.27 & 0.39 & 0.59 & 0.36 \\
\hline & $1 \& 2$ & W & W & 1.69 & 2.65 & 3.69 & 1.76 & 3.53 & 3.56 & 3.09 & 0.09 & 0.34 & 0.51 & 0.23 & 0.45 & 0.39 & 0.37 \\
\hline & 1 & $\mathrm{Bw}$ & $\mathrm{Bw}$ & 1.98 & 2.96 & 4.89 & 1.51 & 2.11 & 2.14 & 2.13 & 0.16 & 0.18 & 1.16 & 0.12 & 0.14 & 0.17 & 0.17 \\
\hline & 2 & $\mathrm{Bw}$ & W & 1.90 & 2.41 & 4.05 & 1.40 & 2.59 & 3.47 & 2.50 & 0.24 & 0.34 & 0.54 & 0.18 & 0.2 & 0.39 & 0.29 \\
\hline & 1 & $\mathrm{M}$ & M & 2.86 & 4.07 & 3.26 & 1.92 & 1.23 & 3.51 & 3.06 & 0.30 & 0.26 & 0.39 & 0.21 & 0.21 & 0.27 & 0.27 \\
\hline & 2 & M & W & 2.42 & 5.39 & 6.35 & 1.69 & 2.80 & 5.95 & 4.10 & 0.29 & 0.73 & 1.16 & 0.17 & 0.25 & 0.92 & 0.51 \\
\hline & 1 & $\mathrm{Bm}$ & $\mathrm{Bm}$ & 1.92 & 4.01 & 6.28 & 2.11 & 1.94 & 3.38 & 2.75 & 0.46 & 0.48 & 0.45 & 0.44 & 0.44 & 0.44 & 0.45 \\
\hline & 2 & $\mathrm{Bm}$ & W & 18.82 & 2.41 & 2.45 & 3.31 & 9.09 & 5.19 & 4.25 & 0.64 & 0.42 & 1.18 & 0.47 & 0.92 & 0.41 & 0.56 \\
\hline \multirow{8}{*}{ 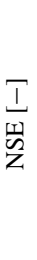 } & $1 \& 2$ & $\mathrm{D}$ & W & 0.69 & 0.76 & 0.8 & 0. & 0.7 & 0. & & & 0.76 & 0.8 & & 0 . & 0.88 & 0.80 \\
\hline & $1 \& 2$ & W & W & 0.74 & 0.81 & 0.89 & 0.87 & 0.82 & 0.94 & 0.84 & 0.74 & 0.80 & 0.88 & 0.84 & 0.81 & 0.92 & 0.83 \\
\hline & 1 & $\mathrm{Bw}$ & $\mathrm{Bw}$ & 0.81 & 0.84 & 0.90 & 0.88 & 0.79 & 0.91 & 0.86 & 0.81 & 0.81 & 0.90 & 0.83 & 0.78 & 0.87 & 0.82 \\
\hline & 2 & $\mathrm{Bw}$ & W & 0.73 & 0.82 & 0.89 & 0.86 & 0.82 & 0.93 & 0.84 & 0.73 & 0.80 & 0.88 & 0.82 & 0.82 & 0.90 & 0.82 \\
\hline & 1 & $\mathrm{M}$ & $\mathrm{M}$ & 0.78 & 0.88 & 0.87 & 0.80 & 0.64 & 0.92 & 0.84 & 0.77 & 0.87 & 0.84 & 0.72 & 0.58 & 0.89 & 0.81 \\
\hline & 2 & M & W & 0.68 & 0.82 & 0.88 & 0.79 & 0.76 & 0.91 & 0.81 & 0.68 & 0.82 & 0.87 & 0.77 & 0.75 & 0.89 & 0.80 \\
\hline & 1 & $\mathrm{Bm}$ & $\mathrm{Bm}$ & 0.66 & 0.83 & 0.83 & 0.87 & 0.76 & 0.82 & 0.83 & 0.67 & 0.78 & 0.73 & 0.85 & 0.70 & 0.79 & 0.76 \\
\hline & 2 & $\mathrm{Bm}$ & W & 0.64 & 0.71 & 0.77 & 0.84 & 0.79 & 0.81 & 0.78 & 0.69 & 0.70 & 0.75 & 0.82 & 0.79 & 0.83 & 0.77 \\
\hline \multirow{8}{*}{$\frac{\sqrt{8}}{\delta^{8}}$} & $1 \& 2$ & $\mathrm{D}$ & W & 1.85 & 1.65 & 1.28 & 1.06 & 1.36 & 1.10 & 1.32 & 18 & 1.65 & 1.3 & 11 & 1. & 1.10 & 1.35 \\
\hline & $1 \& 2$ & W & W & 1.67 & 1.46 & 1.14 & 0.93 & 1.24 & 0.79 & 1.19 & 1.67 & 1.50 & 1.21 & 1.03 & 1.26 & 0.87 & 1.23 \\
\hline & 1 & $\mathrm{Bw}$ & $\mathrm{Bw}$ & 1.36 & 1.41 & 1.05 & 0.89 & 1.31 & 0.86 & 1.18 & 1.36 & 1.51 & 1.08 & 1.02 & 1.33 & 1.05 & 1.20 \\
\hline & 2 & $\mathrm{Bw}$ & W & 1.71 & 1.43 & 1.12 & 0.96 & 1.22 & 0.85 & 1.1 & 1.71 & 1.52 & 1.2 & 1.0 & 1.2 & 1.00 & 1.24 \\
\hline & 1 & $\mathrm{M}$ & M & 1.29 & 1.04 & 1.13 & 1.07 & 1.59 & 0.78 & 1.10 & 1.32 & 1.09 & 1.28 & 1.26 & 1.72 & 0.94 & 1.27 \\
\hline & 2 & M & W & 1.88 & 1.42 & 1.21 & 1.19 & 1.44 & 0.96 & 1.31 & 1.88 & 1.42 & 1.25 & 1.24 & 1.46 & 1.03 & 1.33 \\
\hline & 1 & $\mathrm{Bm}$ & $\mathrm{Bm}$ & 1.42 & 1.11 & 1.28 & 0.80 & 1.20 & 1.05 & 1.16 & 1.42 & 1.25 & 1.60 & 0.86 & 1.35 & 1.13 & 1.30 \\
\hline & 2 & $\mathrm{Bm}$ & W & 2.00 & 1.84 & 1.67 & 1.04 & 1.34 & 1.37 & 1.52 & 1.85 & 1.87 & 1.75 & 1.09 & 1.34 & 1.30 & 1.54 \\
\hline \multirow{8}{*}{$\frac{\bar{s}}{\infty}$} & $1 \& 2$ & $\mathrm{D}$ & W & 0.34 & 0.03 & 0.06 & 0.10 & -0.09 & 0.23 & 0.0 & 0.22 & 0.00 & -0.15 & 0.03 & -0.06 & 0.11 & 0.02 \\
\hline & $1 \& 2$ & W & W & 0.21 & -0.06 & -0.28 & -0.02 & -0.14 & 0.14 & -0.04 & -0.04 & -0.03 & -0.10 & 0.11 & -0.03 & -0.02 & -0.03 \\
\hline & 1 & $\mathrm{Bw}$ & $\mathrm{Bw}$ & -0.01 & -0.20 & -0.39 & -0.11 & -0.20 & -0.07 & -0.16 & -0.07 & -0.01 & 0.03 & 0.07 & 0.00 & 0.08 & 0.02 \\
\hline & 2 & $\mathrm{Bw}$ & W & 0.16 & -0.14 & -0.20 & 0.00 & 0.01 & 0.10 & 0.01 & -0.03 & -0.03 & 0.03 & 0.04 & -0.02 & 0.09 & 0.00 \\
\hline & 1 & M & M & -0.17 & -0.30 & -0.07 & -0.24 & -0.13 & -0.16 & -0.16 & 0.05 & -0.07 & 0.07 & 0.08 & 0.12 & -0.05 & 0.06 \\
\hline & 2 & M & W & 0.07 & -0.28 & -0.32 & -0.22 & 0.03 & 0.13 & -0.10 & -0.04 & -0.14 & -0.09 & 0.00 & -0.01 & -0.05 & -0.05 \\
\hline & 1 & $\mathrm{Bm}$ & $\mathrm{Bm}$ & 0.11 & -0.09 & -0.13 & -0.07 & -0.05 & -0.08 & -0.08 & 0.03 & -0.07 & -0.17 & -.01 & 0.03 & -0.05 & -0.03 \\
\hline & 2 & $\mathrm{Bm}$ & W & 0.43 & 0.23 & 0.10 & 0.00 & 0.07 & 0.36 & 0.17 & -0.04 & -0.04 & 0.07 & 0.00 & -0.07 & -0.04 & -0.04 \\
\hline
\end{tabular}



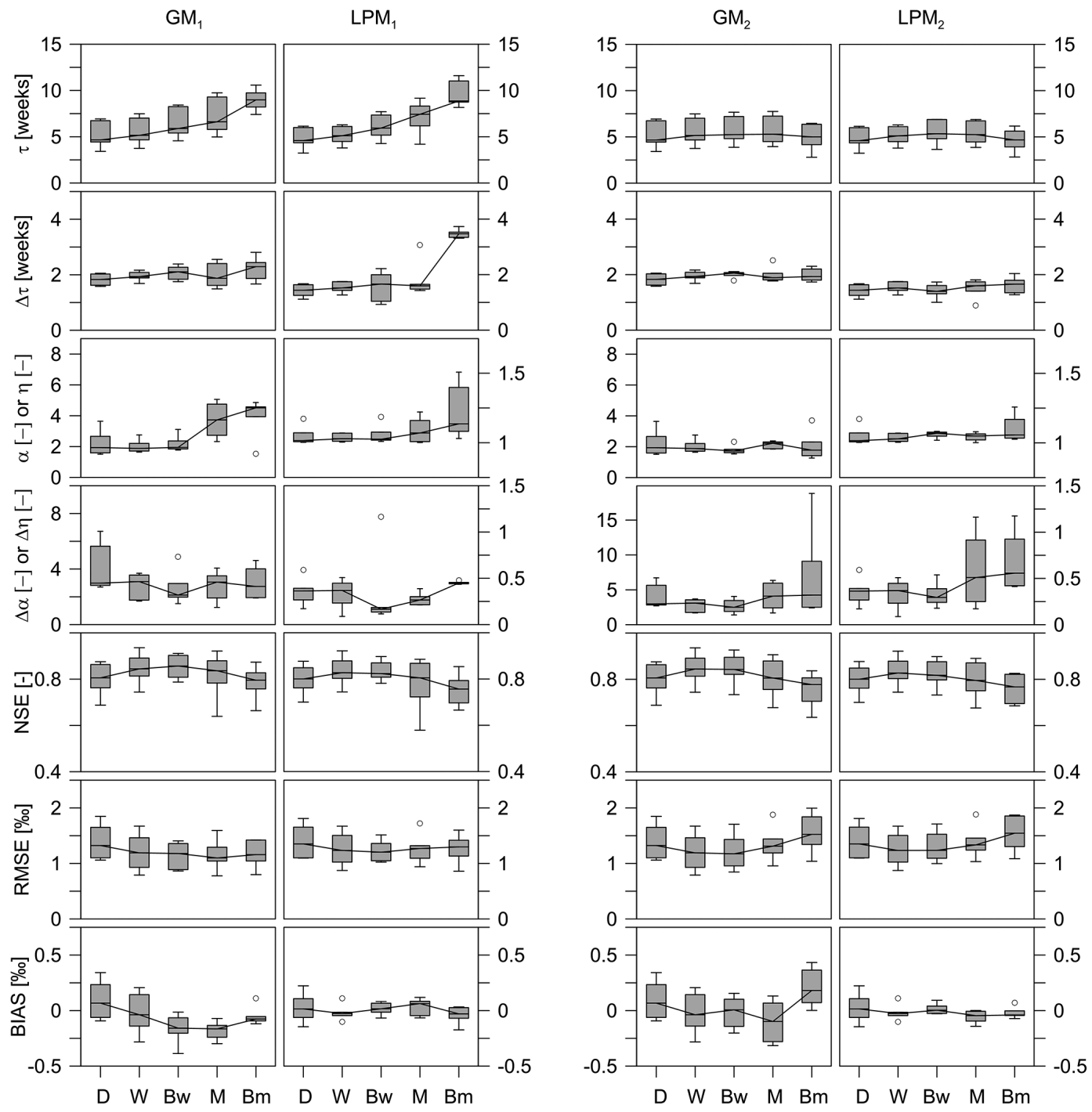

Figure 2. Comparison of predictions for soil water sites using gamma (GM) and linear-piston (LPM) lumped models. Subscript in the model name stands for the type of scenario: Sc1 is aggregation of sampling frequency in the rainfall and also in the effluent, Sc2 is aggregation of sampling frequency only in rainfall data. Acronyms in the $x$ axis of all plots stands for five types of data resolution: $\mathrm{D}$ is daily, W is weekly, Bw is bi-weekly, $\mathrm{M}$ is monthly and $\mathrm{Bm}$ is bi-monthly. Box plots markers correspond to quartiles and median values (-). The length of whiskers is limited to 1.5 times the width of the box and values located further away below the first quartile or above the third quartile are considered extreme ones (o).

Estimations for GM's $\alpha$ parameter showed a similar median value for daily, weekly or bi-weekly sampling frequencies $(\widetilde{\alpha}$ varied from 1.88 to 1.95$)$, while it was larger for coarser time resolutions; for example, the $\alpha$ value was 3.73 for monthly and 4.55 for bi-monthly data. Using LPM, the variation of the median value of $\eta$ slightly changed among time resolutions (e.g., $\widetilde{\eta}$ varied from 1.02 for daily up to 1.14 for bi-monthly data). However, results for particular sites for coarser data, such as monthly or bi-monthly, showed larger values (e.g., for the A soil site $\eta$ varied from 1.02 for daily data to 1.40 for bi-monthly data). Median values of GLUE-based uncertainties for these parameters did not show a clear trend or significant variation as a function of the time resolution. In all cases $\overline{\Delta \alpha}$ varied between 2.13 and 3.09 , while $\widetilde{\Delta \eta}$ varied from 0.17 to 0.45 .

As a typical case among soil water sites, results for every sampling resolution using the GM are depicted in Fig. 3 respectively showing the convergence of model parameters, the simulated versus observed $\delta^{18} \mathrm{O}$, and the TTD.

\subsubsection{Type 2 scenarios - varying resolution of rain data and fixed resolution of soil water isotope data}

For both models, the NSE, RMSE and BIAS of the best predictions followed similar trends to that of type 1 scenarios. 

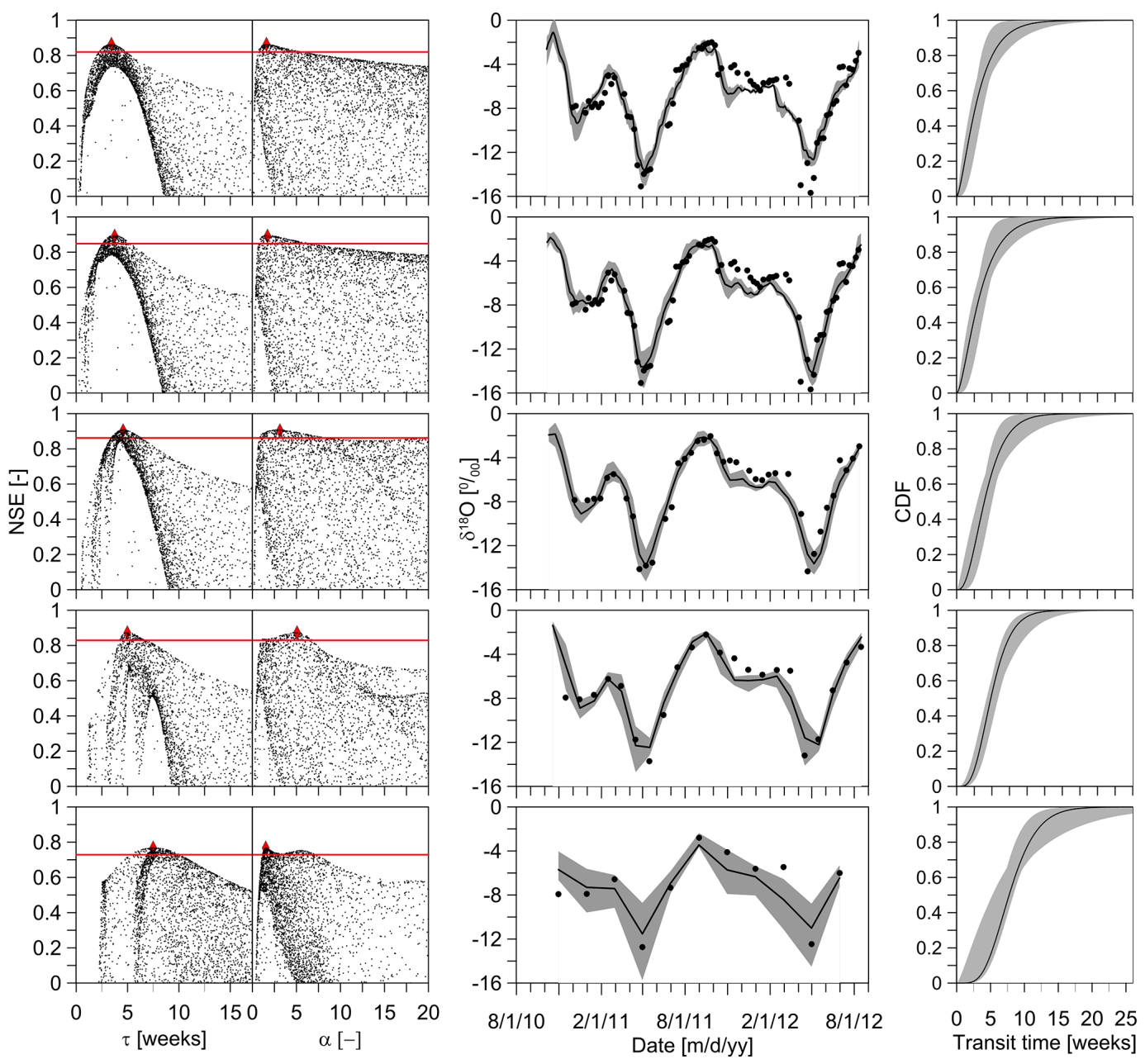

Figure 3. Predicted results for the soil water site $\mathrm{C}$ using the gamma lumped model (GM). Results are ranged from top to bottom according to the data resolution: daily (top panels), weekly, bi-weekly, monthly and bi-monthly (bottom panels). Left column panels show dotty plots for the model parameters ( $\tau$ and $\alpha$ ) according to NSE using Monte Carlo random simulations (GLUE approach). Red line shows the feasible range of behavioral solutions of model parameters as a $5 \%$ of the top best prediction (red diamond). Center column panels show the measured (black filled circles) and simulated $\delta^{18} \mathrm{O}$ (the black line and the shaded area represent the best possible solution and its range of variation according to the 5-95\% of weighted quantiles derived from the confidence limits of behavioral solutions shown in the left column). Right column panels: soil water residence time distribution function corresponding to the best NSE; gray shaded area in each plot corresponds to the range of possible shapes of the distribution function.

When compared to results from the reference sampling resolution, NSE values were higher for weekly and bi-weekly input data. For instance, using GM the median value of the best NSE was 0.81 for daily and 0.84 for both weekly and bi-weekly data. Monthly data sets provided predictions with similar efficiencies than daily, while for bi-monthly data the median value of NSE was 0.78 , the lowest among all sampling resolutions of type 2 scenarios.

Compared to type 1 scenarios, predictions of parameter results and uncertainties among time resolutions were more stable. Using GM, $\widetilde{\tau}$ for the finest and coarsest time resolutions varied between 4.66 and 5.00 weeks, while $\widetilde{\Delta \tau}$ showed extreme values between 1.83 and 2.06 weeks. The variation of $\alpha$ between sampling frequencies was also smaller: $\widetilde{\alpha}$ was between 1.73 and 2.23 , while $\widetilde{\Delta \alpha}$ was similar to results from type 1 scenarios (e.g., smaller uncertainties for finer than coarser resolution data sets: 2.99 for daily and 4.25 for bi-monthly data). However, there were larger uncertainties for particular sites when low resolution data sets were used (e.g., the most extreme case was found for the A site where there was a $\Delta \alpha$ increase from 2.83 using daily data to 18.82 using bi-monthly data). Using LPM the trends and values were similar to the ones obtained with GM. Comparing the daily and bi-monthly time resolutions $\widetilde{\tau}$ varied from 4.59 to 4.68 weeks, and their respective $\widetilde{\Delta \tau}$ ranged from 1.44 to 1.66 weeks. The median value for $\eta$ was around 1 for all sampling frequencies. Although small for all cases, $\widetilde{\Delta \eta}$ was 

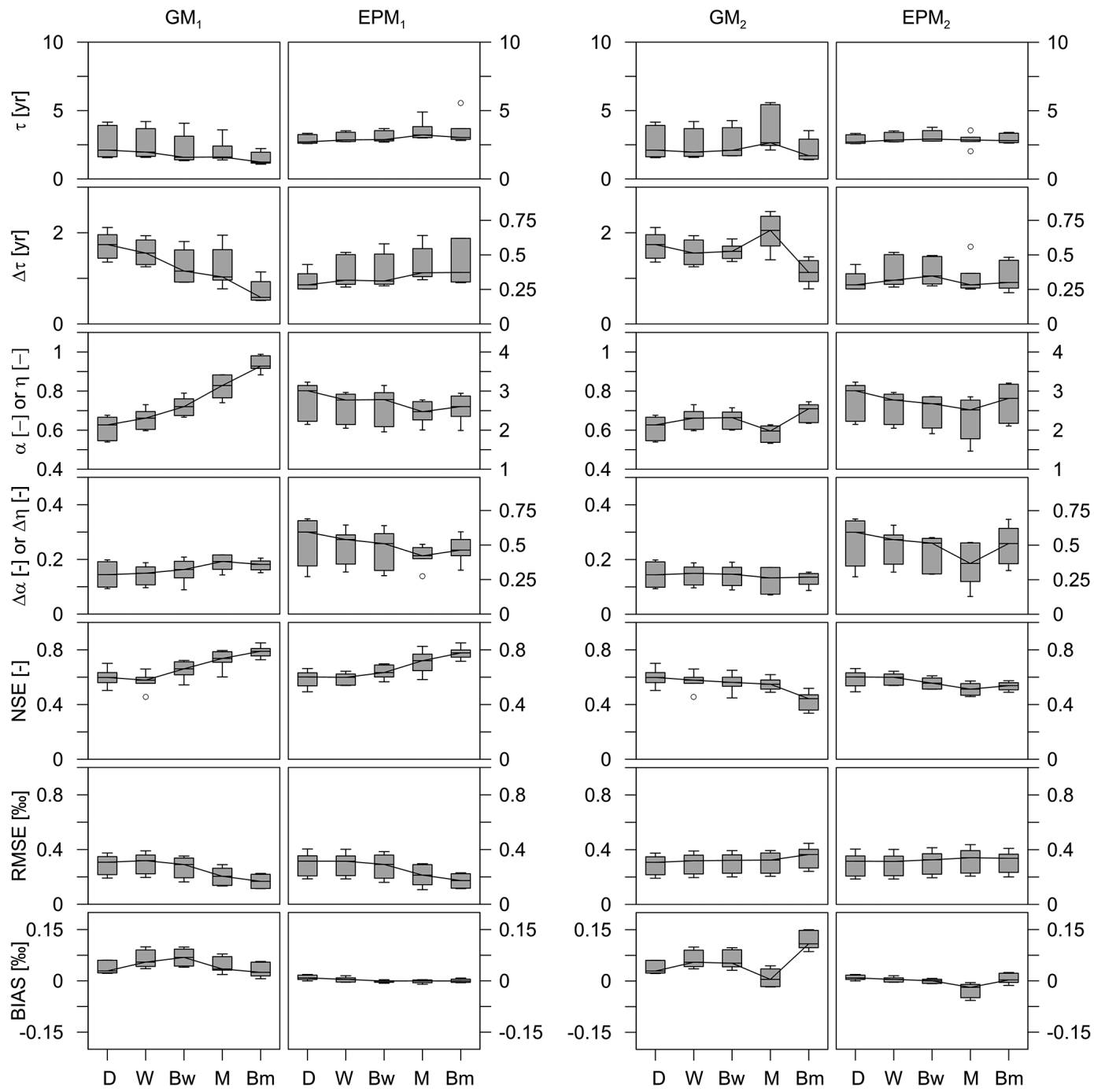

Figure 4. Comparison of predictions for stream water sites using the gamma (GM) and exponential-piston (EPM) lumped models. The subscript in the model name stands for the type of scenario: Sc1 is aggregation of sampling frequency in the rainfall and also in the effluent, $\mathrm{Sc} 2$ is aggregation of sampling frequency only in rainfall data. Acronyms in the $x$ axis of all plots stands for five types of data resolution: D is daily, W is weekly; $\mathrm{Bw}$ is bi-weekly, $\mathrm{M}$ is monthly and $\mathrm{Bm}$ is bi-monthly. Box plots markers correspond to quartiles and median values are shown (-). The length of whiskers is limited to 1.5 times the width of the box and values located further away below the first quartile or above the third quartile are considered extreme ones (o).

larger for coarser than for finer time resolution data: 0.36 for daily up to 0.56 for bi-monthly data.

\subsection{Stream water (Table 2, Fig. 4)}

\subsubsection{Type 1 scenarios - varying resolution of rain and stream water isotope data}

Regardless of the used model, the best solutions showed an increasing trend of NSE values from finer to coarser data resolutions. For GM, median NSE values of 0.74 and 0.79 were reached using monthly and bi-monthly data while for daily data it was 0.60. Analogously, RMSE values were smaller for coarse data resolutions. Median RMSE declined from
$0.31 \%$ for daily to $0.17 \%$ for bi-monthly data. BIAS remained small for all cases, with an average value of $0.04 \%$. For EPM we obtained similar trends and values.

Using GM, parameter results revealed lower values of $\tau$ for coarser time resolutions data when compared to daily data resolution, e.g., $\widetilde{\tau}$ went from $2.10 \mathrm{yr}$ for daily data to $1.23 \mathrm{yr}$ for bi-monthly data. Furthermore, a clear decreasing trend of uncertainty lengths was detected. In general $\Delta \tau$ was smaller for coarser than for finer time resolution data, e.g., $1.74 \mathrm{yr}$ for daily and $0.58 \mathrm{yr}$ for bi-monthly data. For the GM's $\alpha$ showed a trend to higher values proportional to the decrease of sampling resolution: $\widetilde{\alpha}$ was 0.63 for the reference while it reached a value of 0.93 for bi-monthly data. 


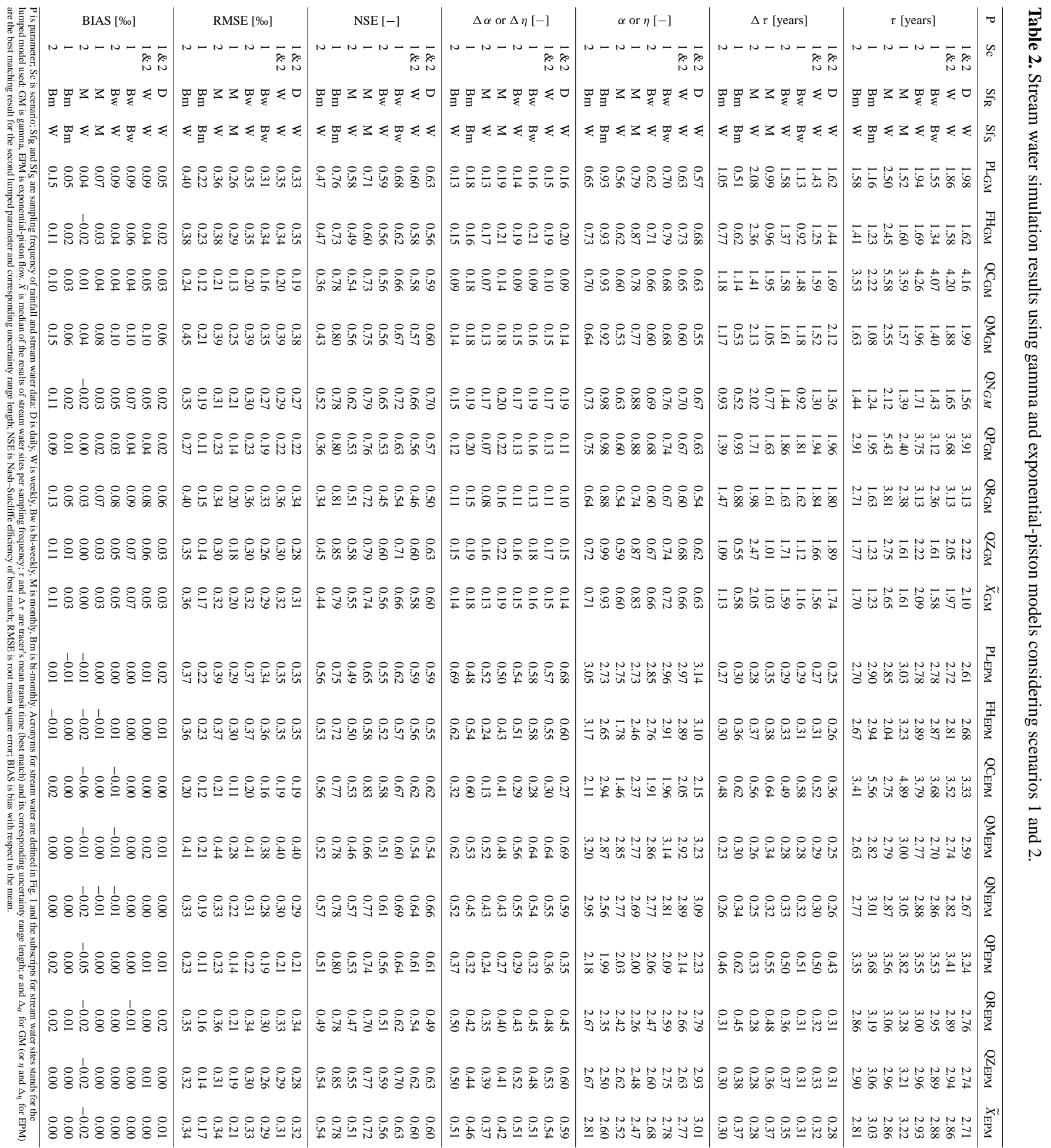



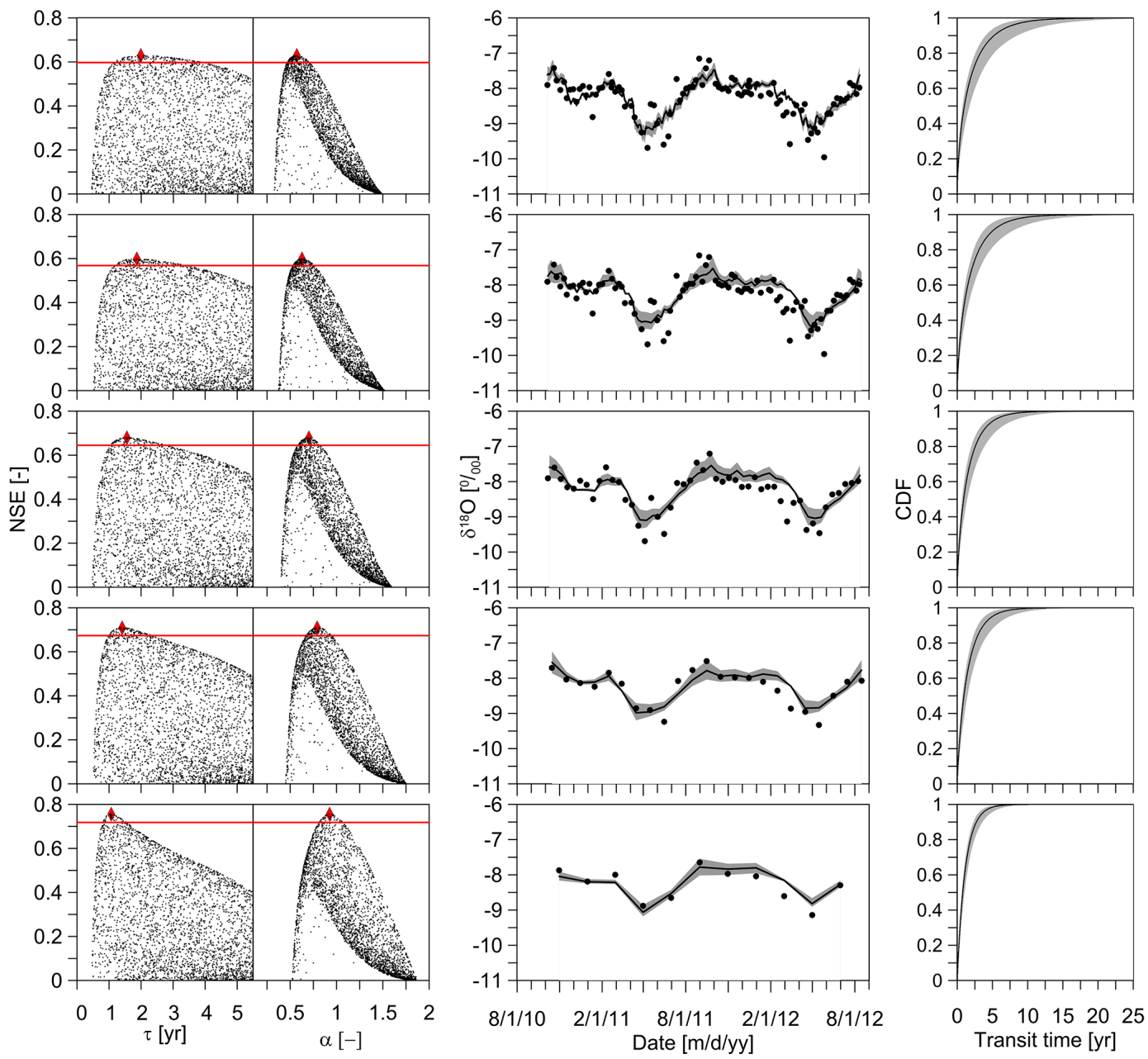

Figure 5. Predicted results for the stream water site PL using the gamma lumped model (GM). Results are ranged from top to bottom according to the data resolution: daily (top panels), weekly, bi-weekly, monthly and bi-monthly (bottom panels). Left column panels show dotty plots for the model parameters ( $\tau$ and $\alpha$ ) according to NSE using Monte Carlo random simulations (GLUE approach). Red line shows the feasible range of behavioral solutions of model parameters as a $5 \%$ of the top best prediction (red diamond). Center column panels show the measured (black filled circles) and simulated $\delta^{18} \mathrm{O}$ (the black line and the shaded area represent the best possible solution and its range of variation according to the 5-95\% of weighted quantiles derived from the confidence limits of behavioral solutions shown in the left column). Right column panels: stream water transit time distribution function corresponding to the best NSE; gray shaded area in each plot corresponds to the range of possible shapes of the distribution function.

The median values of uncertainty lengths for this parameter $(\widetilde{\Delta \alpha})$ only slightly increased from daily $(0.14)$ to the coarsest data resolution (0.18). On the other hand, for the same conditions but using EPM, $\tau$ values only slightly increased with coarser time resolutions ( $\widetilde{\tau}$ varied little from 2.71 to $3.03 \mathrm{yr}$ between daily and bi-monthly data resolutions). The variation of $\Delta \tau$ was also small between sampling frequencies. Extreme $\widetilde{\Delta \tau}$ values were accounted for daily and bi-monthly data: 0.28 and $0.37 \mathrm{yr}$, respectively. The parameter $\eta$, as a median value among sites, depicted subtle smaller values for lower sampling frequencies. It decreased from 3.01 for daily data to 2.60 for bi-monthly ones. In general, $\Delta \eta$ slightly decreased for coarser time resolutions: $\overline{\Delta \eta}$ dropped from 0.59 using daily to 0.46 using bi-monthly data.
Results for particular sites follow nearly the trends described by the median values for all analyzed sites. Similarly to results depicted in Fig. 3 for the soil site C, Fig. 5 depicts the variation in results for different data resolutions applied to the stream water of the main outlet of the catchment (PL).

\subsubsection{Type 2 scenarios - varying resolution of rain data and fixed resolution of stream water isotope data}

Contrary to type 1 scenarios, the median NSE decreased for coarser temporal resolution data; e.g., NSE for GM dropped from 0.60 using daily data to 0.44 using bi-monthly ones. The value of RMSE and BIAS remained low amidst the temporal resolutions. Median RMSE was around $0.33 \%$ while 
the largest BIAS was $0.11 \%$. The trend of NSE values for EPM was similar to GM, although less sensitive to temporal resolution data. It declined from a median of 0.60 for daily data to 0.54 for bi-monthly. RMSE and BIAS yielded for GM and EPM were comparable.

Similar to soil waters, for both models the variation of parameter results among diverse sampling frequencies was smaller than for the corresponding type 1 scenarios. When GM was used, $\widetilde{\tau}$ predictions varied from $2.10 \mathrm{yr}$ for daily data to $1.70 \mathrm{yr}$ for bi-monthly. The largest estimated $\widetilde{\alpha}$ was 0.71 (using bi-monthly data) which was not far from the predicted value using daily data: 0.63 , considering that the range of behavioral solutions for this parameter was around 0.14 for every case. Uncertainty ranges for both parameters between diverse temporal resolution data yielded similar average estimations: $\overline{\Delta \tau} \approx 1.6$ yr and $\widehat{\Delta \alpha} \approx 0.14$. Also for the EPM the best solution parameters varied slightly amongst data resolutions. For example, considering daily and bi-monthly sampling frequencies $\tilde{\tau}$ predictions varied from 2.71 to $2.81 \mathrm{yr}$ and $\widetilde{\eta}$ from 3.01 to 2.81 . Uncertainties for both parameters were small and similar between time resolutions: $\overline{\Delta \tau}$ ranged from 0.28 to $0.30 \mathrm{yr}$ and $\widetilde{\Delta \eta}$ from 0.59 to 0.51 .

\section{Discussion}

Results indicate that in some cases, like the present one, it is not sufficient to assess the supremacy of one model over another based only on their performance; instead, additional knowledge on the conceptual functioning of the studied system is necessary. For instance in Timbe et al. (2014), where a weekly time step was considered, EPM and LPM predictions showed fewer uncertainty ranges (for stream and soil waters, respectively) when compared to predictions provided by a GM, which in counterpart provided better fitting efficiencies for most of the cases. The current results corroborate those previous findings. Further research is needed to identify the best TTD not only in terms of statistical performance; meanwhile, the use of any of the analyzed models cannot be discarded.

For studies dealing with coarse stable isotope data sets (e.g., monthly or bi-monthly), considering the differences of the performances between data sets of diverse sampling resolutions, the uncertainties associated to the predictions should be acknowledged and considered at the moment of the evaluation of hypotheses associated to these results. Monthly sampling resolution and monthly data are still frequently used in stable water isotope studies when either the effort or the costs are too high to realize a higher sampling frequency (e.g., Goller et al., 2005; Rodgers et al., 2005; Viville et al., 2006; Liu et al., 2007; Rock and Mayer, 2007; Chen et al., 2012), which goes in line with a large share of observation points of the Global Network of Isotopes in Precipitation and Rivers (GNIP) of the I.A.E.A.-W.M.O.

\subsection{Sensitivity of model-parameter results to sampling frequency}

In general, for soil and stream waters, model parameters for type 1 scenarios (Tables 1 and 2, Figs. 2-5): $\tau, \alpha$ and $\eta$, showed distinct values between results from finer and lower data resolutions. Keeping this finding in mind, whenever a high-resolution isotope sampling is feasible, a sensitivity analysis considering the effect of sampling frequency should be a common part of the workflow while applying lumped-parameter models. This practice would help to build a broader database on the sensitivity of lumped convolution modeling to sampling frequencies, which might be useful to correct effects caused by coarse sampling frequencies. In recent literature only two studies dealing with the sampling frequency effect issue could be found: Hrachowitz et al. (2010) using the gamma distribution model and Birkel et al. (2010) through adding information from tracers to a lumped-conceptual hydrological model.

For soil waters, an increasing trend of $\tau$ predictions related to a decrease of sampling data frequency was clear for GM and LPM. Using GM, best predictions for $\alpha$ were similar for time resolutions up to bi-weekly sampling ( $\alpha \approx 1.9$ ), but they were significantly higher for coarser data resolutions.

Using GM for stream waters, parameter predictions depicted a different trend than found for soil waters: $\tau$ yielded lower values for decreasing input resolution data. This descending trend matched the increasing trend of $\alpha$ predictions. The trend depicted by our results differs from the one obtained by Hrachowitz et al. (2011) who applied the same distribution function and convolution method to chloride data in a headwater catchment in Scotland. In their case, a decreasing sampling frequency went hand in hand with a decreasing trend of $\alpha$, which consequently affected the estimations for $\tau$, resulting in systematically larger values. Even though any further comparison of the two studies is difficult, as they represent two different hydrological systems and therefore favor different distribution functions and shape parameters to describe the transport processes at hand, it can be seen that the MTTs greatly differ in accordance with the chosen sampling frequency.

Considering the GLUE-based uncertainties derived from type 1 scenarios, results between soil and stream waters were contrasting. For soil waters the uncertainty magnitudes $\Delta \tau$ remained similar with decreasing time resolution while for stream waters they were systematically shorter. By using type 2 scenarios (Tables 1 and 2, Figs. 2 and 4), where the same weekly temporal resolution of observed data at outflows was kept for the calibration of models, additional insights on the degree of the mismatch of coarse data resolutions compared to finer ones were provided. For these cases, the NSE, RMSE and BIAS of the predictions were in general poorer for low temporal resolutions, hinting towards a higher reliability of finer resolution data sets. Besides the fact that parameter results derived from finer resolution data sets were 
more similar between each other, they did not show marked trends of either overestimations or underestimations as compared to using type 1 scenarios.

For our analyses, given the subtle divergence of results when using daily, weekly or even bi-weekly sampling resolutions, we consider them as adequate for the estimation of MTTs and TTDs. It should be noted that this finding is valid for semi-steady-state conditions of waters. In this regard, the utility of the highest sampling resolution, as daily or even sub-daily, could be noticeable when temporal dynamics are to be considered. In this regard Birkel et al. (2010) provided insights when dealing with the sampling frequency as part of the evaluation of the performance of a lumpedconceptual flow-tracer model. They found that the use of daily isotope data from rainfall and stream water, when compared to weekly or bi-weekly, besides providing higher fitting efficiencies, was beneficial for the conceptualization and calibration of that model.

\subsection{Comparison of distribution functions}

Considering all the analyzed sampled frequencies, according to NSE values, GM performed slightly better than the other two models (Tables 1 and 2). However, GLUE-based uncertainties were also larger for this model (Figs. 2 and 4), hindering the clear preference of one model over another. This finding goes in line with previous insights in the same research area (Timbe et al., 2014) in which a fixed weekly based sampling frequency was used to infer MTTs and TTDs.

For soil waters LPM yielded similar $\tau$ predictions to those of GM, thereby, justifying the use of linear functions such as LPM as a first approximation, despite of presenting a simplification of the water movement of real systems. On the other hand, GM was characterized by a delayed occurrence of the tracer's peak signal $(\alpha \approx 2)$.

For the case of stream waters, the comparison of predicted TTD shows that EPM traces a peak signal delayed over time. We estimated $\eta$ values between 2.15 and 3.23, the largest values we found in related studies that used the same distribution function. Reported values are normally lower than 2 (e.g., Hrachowitz et al., 2009; Katsuyama et al., 2009; McGuire and McDonnell, 2006; Viville et al., 2006; Kabeya et al., 2006), indicating that a large portion of old water is released first to the river as depicted by the isotopic composition of the stream. On the contrary, when analyzing the behavior of water flow as derived from GM, the tracer signal's peak at the outflow occurs instantaneously, meaning that a considerable portion of the event rainfall water rapidly contributes to discharge, as for instance via lateral flow from near-surface deposits. Over time, the tracer signal decreases (for either EPM or GM), but once again the implications are different for both models comparing their flow recessions. As shown in Timbe et al. (2014) for weekly data, the tracer signal decreases more rapidly for EPM than for GM. Thus, depending on which distribution function is used, the inter- pretation is different. For example, in water management using the EPM predictions one could argue that the effects of contamination of water sources will not be immediately reflected in the river water and further that its effect will be rather quickly disappearing. Contrary, inferences provided by a gamma distribution would tell that pollutants in the catchment would have an instantaneous impact on the river water and that the effect will sustain longer over time.

Considering a gamma distribution for the analyzed streams, $\tau$ varied between 1.62 and $4.16 \mathrm{yr}$ and $\alpha$ between 0.54 and 0.68 , using finer sampling resolutions. This range of $\alpha$ values is similar to findings from other tracer studies on stream water using spectral analyses and highresolution samples of chloride. Kirchner et al. (2000) demonstrated that an $\alpha$ value of approximately 0.5 provides a more proper representation of several stream waters in Wales. As stated by Soulsby et al. (2010) gamma distributions with $\alpha<1$ are most suitable to represent non-linear processes. Similarly several other studies found $\alpha$ values significantly smaller than 1 (McGuire et al., 2005; Hrachowitz et al., 2009, 2010; Godsey et al., 2010; Kirchner et al., 2010; Speed et al., 2010; Birkel et al., 2012; Heidbüchel et al., 2012; MuñozVillers and McDonnell, 2012). On the other hand, our results reported that when coarse temporal resolutions were used (monthly or bi-monthly), the value of $\alpha$ approached 1, which could lead to erroneous deductions.

Bearing in mind that each TTD describes different flow characteristics although they could yield similar performances in terms of fitting efficiencies or uncertainties (e.g., LPM versus GM), for our study catchment additional insights (e.g., tracer data associated with different flow paths) are required in order to correctly unveil the prevailing TTD, as solely relying on model performances could lead to misleading results. In this regard, studies at smaller spatial scales using high sampling frequencies and time-variant conditions should be performed in order to cover a wider spectral range of the different water sources.

\section{Conclusions}

Environmental tracer data of rainfall, stream and soil water were collected in the San Francisco catchment with the objective to delineate the reliability of transit time predictions as a function of the input data resolution. The collected information was used to test the prediction accuracy of commonly used lumped models with respect to sampling frequency. Compared to results from coarse data sets, finer temporal resolutions provided more similar outputs. Overall, discrepancies between predictions of diverse sampling frequencies point out that the assessment of the convergence and sensitivity of model parameters is essential for defining a TTD through model calibration. Especially for waters with dampened isotopic signals (i.e., stream waters), model parameters seem to be highly sensitive to sampling frequencies, consid- 
erably increasing the risk of misinterpretation of the underlying processes.

The study clearly demonstrates that estimations of the TTD for catchments with similar characteristics or located in the same region using different frequencies of data sampling provides an additional source of uncertainty, which might hinder a correct model comparison and misrepresentation of the water routing system. The present research also provides a better framework for future related research in the San Francisco basin and similar basins in the Andean mountain region. Based on the new insights presented in this manuscript more elaborated sampling campaigns could be undertaken, which would contribute to a more efficient management of the water resources of Andean and similar mountain basins.

Acknowledgements. The authors are grateful to Karina Feijo for her valuable help during field work and to Irene Cardenas for the assistance provided during the multitude of lab analyses. Furthermore, we like to acknowledge the financial support of the German Research Foundation (DFG, BR2238/4-2) and the Secretaría Nacional de Educación Superior, Ciencia, Tecnología e Innovación (SENESCYT), without which this research could not have been realized. Thanks are also due to the reviewers (Stefan Seeger and one anonymous referee) and the Editor, Markus Hrachowitz, for helpful comments and suggestions that substantially improved the final version of this paper.

Edited by: M. Hrachowitz

\section{References}

Amin, I. E. and Campana, M. E.: A general lumped parameter model for the interpretation of tracer data and transit time calculation in hydrologic systems, J. Hydrol., 179, 1-21, doi:10.1016/0022-1694(95)02880-3, 1996.

Barnes, C. J. and Bonell, M.: Application of unit hydrograph techniques to solute transport in catchments, Hydrol. Process., 10, 793-802, doi:10.1002/(SICI)10991085(199606)10:6<793::AID-HYP372>3.3.CO;2-B, 1996.

Beck, E., Kottke, I., Bendix, J., Makeschin, F., and Mosandl, R.: Gradients in a tropical mountain ecosystem - a synthesis, in: Gradients in a Tropical Mountain Ecosystem of Ecuador, vol. 198, edited by: Beck, E., Bendix, J., Kottke, I., Makeschin, F., and Mosandl, R., Springer, Berlin, 451-463, 2008.

Bendix, J., Rollenbeck, R., Fabian, P., Emck, P., Richter, M., and Beck, E.: Climate variability, in: Gradients in a Tropical Mountain Ecosystem of Ecuador, edited by: Beck, E., Bendix, J., Kottke, I., Makeschin, F., and Mosandl, R., Springer, Berlin, 281290, 2008.

Beven, K. and Freer, J.: Equifinality, data assimilation, and uncertainty estimation in mechanistic modelling of complex environmental systems using the GLUE methodology, J. Hydrol., 249, 11-29, doi:10.1016/S0022-1694(01)00421-8, 2001.

Birkel, C., Dunn, S. M., Tetzlaff, D., and Soulsby, C.: Assessing the value of high-resolution isotope tracer data in the stepwise development of a lumped conceptual rainfall-runoff model, Hydrol. Process., 24, 2335-2348, doi:10.1002/hyp.7763, 2010.

Birkel, C., Tetzlaff, D., Dunn, S. M., and Soulsby, C.: Using lumped conceptual rainfall-runoff models to simulate daily isotope variability with fractionation in a nested mesoscale catchment, Adv. Water Resour., 34, 383-394, doi:10.1016/j.advwatres.2010.12.006, 2011.

Birkel, C., Soulsby, C., Tetzlaff, D., Dunn, S., and Spezia, L.: Highfrequency storm event isotope sampling reveals time-variant transit time distributions and influence of diurnal cycles, Hydrol. Process., 26, 308-316, doi:10.1002/hyp.8210, 2012.

Botter, G., Bertuzzo, E., and Rinaldo, A.: Transport in the hydrologic response: Travel time distributions, soil moisture dynamics, and the old water paradox, Water Resour. Res., 46, W03514, doi:10.1029/2009WR008371, 2010.

Botter, G., Bertuzzo, E., and Rinaldo, A.: Catchment residence and travel time distributions: The master equation, Geophys. Res. Lett., 38, L11403, doi:10.1029/2011GL047666, 2011.

Capell, R., Tetzlaff, D., Hartley, A. J., and Soulsby, C.: Linking metrics of hydrological function and transit times to landscape controls in a heterogeneous mesoscale catchment, Hydrol. Process., 26, 405-420, doi:10.1002/hyp.8139, 2012.

Chen, J., Liu, X., Wang, C., Rao, W., Tan, H., Dong, H., Sun, X., Wang, Y., and Su, Z.: Isotopic constraints on the origin of groundwater in the Ordos Basin of northern China, Environ. Earth Sci., 66, 505-517, doi:10.1007/s12665-011-1259-6, 2012.

Craig, H.: Standard for reporting concentrations of deuterium and oxygen-18 in natural waters, Science, 133, 1833, doi:10.1126/science.133.3467.1833, 1961.

Crespo, P., Bücker, A., Feyen, J., Vaché, K. B., Frede, H.-G., and Breuer, L.: Preliminary evaluation of the runoff processes in a remote montane cloud forest basin using mixing model analysis and mean transit time, Hydrol. Process., 26, 3896-3910, doi:10.1002/hyp.8382, 2012.

Dewalle, D. R., Edwards, P. J., Swistock, B. R., Aravena, R., and Drimmie, R. J.: Seasonal isotope hydrology of three Appalachian forest catchments, Hydrol. Process., 11, 18951906, doi:10.1002/(SICI)1099-1085(199712)11:15<1895::AIDHYP538>3.3.CO;2-R, 1997.

Fiedler, K. and Beck, E.: Investigating gradients in ecosystem analysis, in: Gradients in a Tropical Mountain Ecosystem of Ecuador, edited by: Beck, E., Bendix, J., Kottke, I., Makeschin, F., and Mosandl, R., Springer, Berlin, 49-54, 2008.

Godsey, S. E., Aas, W., Clair, T. A., de Wit, H. A., Fernandez, I. J., Kahl, J. S., Malcolm, I. A., Neal, C., Neal, M., Nelson, S. J., Norton, S. A., Palucis, M. C., Skjelkvale, B. L., Soulsby, C., Tetzlaff, D., and Kirchner, J. W.: Generality of fractal $1 / f$ scaling in catchment tracer time series, and its implications for catchment travel time distributions, Hydrol. Process., 24, 1660-1671, doi:10.1002/hyp.7677, 2010.

Goettlicher, D., Obregon, A., Homeier, J., Rollenbeck, R., Nauss, T., and Bendix, J.: Land-cover classification in the Andes of southern Ecuador using Landsat ETM plus data as a basis for SVAT modelling, Int. J. Remote Sens., 30, 1867-1886, doi:10.1080/01431160802541531, 2009.

Goller, R., Wilcke, W., Leng, M. J., Tobschall, H. J., Wagner, K., Valarezo, C., and Zech, W.: Tracing water paths through small catchments under a tropical montane rain forest in south 
Ecuador by an oxygen isotope approach, J. Hydrol., 308, 67-80, doi:10.1016/j.jhydrol.2004.10.022, 2005.

Heidbüchel, I., Troch, P. A., Lyon, S. W., and Weiler, M.: The master transit time distribution of variable flow systems, Water Resour. Res., 48, W06520, doi:10.1029/2011WR011293, 2012.

Hrachowitz, M., Soulsby, C., Tetzlaff, D., Dawson, J. J. C., Dunn, S. M., and Malcolm, I. A.: Using long-term data sets to understand transit times in contrasting headwater catchments, J. Hydrol., 367, 237-248, doi:10.1016/j.jhydrol.2009.01.001, 2009.

Hrachowitz, M., Soulsby, C., Tetzlaff, D., Malcolm, I. A., and Schoups, G.: Gamma distribution models for transit time estimation in catchments: Physical interpretation of parameters and implications for time-variant transit time assessment, Water Resour. Res., 46, W10536, doi:10.1029/2010WR009148, 2010.

Hrachowitz, M., Soulsby, C., Tetzlaff, D., and Malcolm, I. A.: Sensitivity of mean transit time estimates to model conditioning and data availability, Hydrol. Process., 25, 980-990, doi:10.1002/hyp.7922, 2011.

Hrachowitz, M., Savenije, H., Bogaard, T. A., Tetzlaff, D., and Soulsby, C.: What can flux tracking teach us about water age distribution patterns and their temporal dynamics?, Hydrol. Earth Syst. Sci., 17, 533-564, doi:10.5194/hess-17-533-2013, 2013.

Kabeya, N., Katsuyama, M., Kawasaki, M., Ohte, N., and Sugimoto, A.: Estimation of mean residence times of subsurface waters using seasonal variation in deuterium excess in a small headwater catchment in Japan, Hydrol. Process., 21, 308-322, doi:10.1002/hyp.6231, 2006.

Katsuyama, M., Kabeya, N., and Ohte, N.: Elucidation of the relationship between geographic and time sources of stream water using a tracer approach in a headwater catchment, Water Resour. Res., 45, W06414, doi:10.1029/2008WR007458, 2009.

Kirchner, J. W., Feng, X. H., and Neal, C.: Fractal stream chemistry and its implications for contaminant transport in catchments, Nature, 403, 524-527, doi:10.1038/35000537, 2000.

Kirchner, J. W., Feng, X. H., and Neal, C.: Catchment-scale advection and dispersion as a mechanism for fractal scaling in stream tracer concentrations, J. Hydrol., 254, 82-101, doi:10.1016/S0022-1694(01)00487-5, 2001.

Kirchner, J. W., Tetzlaff, D., and Soulsby, C.: Comparing chloride and water isotopes as hydrological tracers in two Scottish catchments, Hydrol. Process., 24, 1631-1645, doi:10.1002/hyp.7676, 2010.

Liu, W. J., Liu, W. Y., Li, P. J., Gao, L., Shen, Y. X., Wang, P. Y., Zhang, Y. P., and Li, H. M.: Using stable isotopes to determine sources of fog drip in a tropical seasonal rain forest of Xishuangbanna, SW China, Agr. Forest Meteorol., 143, 80-91, doi:10.1016/j.agrformet.2006.11.009, 2007.

Maloszewski, P. and Zuber, A.: Determining the turnover time of groundwater systems with the aid of environmental tracers, 1. Models and their applicability, J. Hydrol., 57, 207-231, 1982.

Maloszewski, P. and Zuber, A.: Principles and practice of calibration and validation of mathematical-models for the interpretation of environmental tracer data, Adv. Water Resour., 16, 173-190, doi:10.1016/0309-1708(93)90036-F, 1993.

Maloszewski, P., Maciejewski, S., Stumpp, C., Stichler, W., Trimborn, P., and Klotz, D.: Modelling of water flow through typical Bavarian soils: 2. Environmental deuterium transport, Hydrol. Sci. J. - J. Sci. Hydrol., 51, 298-313, doi:10.1623/hysj.51.2.298, 2006.
McGuire, K. J. and McDonnell, J. J.: A review and evaluation of catchment transit time modeling, J. Hydrol., 330, 543-563, doi:10.1016/j.jhydrol.2006.04.020, 2006.

McGuire, K. J., DeWalle, D. R., and Gburek, W. J.: Evaluation of mean residence time in subsurface waters using oxygen-18 fluctuations during drought conditions in the mid-Appalachians, J. Hydrol., 261, 132-149, doi:10.1016/S0022-1694(02)00006-9, 2002.

McGuire, K. J., McDonnell, J. J., Weiler, M., Kendall, C., McGlynn, B. L., Welker, J. M., and Seibert, J.: The role of topography on catchment-scale water residence time, Water Resour. Res., 41, W05002, doi:10.1029/2004WR003657, 2005.

McGuire, K. J., Weiler, M., and McDonnell, J. J.: Integrating tracer experiments with modeling to assess runoff processes and water transit times, Adv. Water Resour., 30, 824-837, doi:10.1016/j.advwatres.2006.07.004, 2007.

Muñoz-Villers, L. E. and McDonnell, J. J.: Runoff generation in a steep, tropical montane cloud forest catchment on permeable volcanic substrate, Water Resour. Res., 48, W09528, doi:10.1029/2011WR011316, 2012.

Nash, J. E. and Sutcliffe, J. V.: River flow forecasting through conceptual models part I - A discussion of principles, J. Hydrol., 10, 282-290, doi:10.1016/0022-1694(70)90255-6, 1970.

Rinaldo, A., Beven, K. J., Bertuzzo, E., Nicotina, L., Davies, J., Fiori, A., Russo, D., and Botter, G.: Catchment travel time distributions and water flow in soils, Water Resour. Res., 47, W07537, doi:10.1029/2011WR010478, 2011.

Rock, L. and Mayer, B.: Isotope hydrology of the Oldman River basin, southern Alberta, Canada, Hydrol. Process., 21, 33013315, doi:10.1002/hyp.6545, 2007.

Rodgers, P., Soulsby, C., Waldron, S., and Tetzlaff, D.: Using stable isotope tracers to assess hydrological flow paths, residence times and landscape influences in a nested mesoscale catchment, Hydrol. Earth Syst. Sci., 9, 139-155, doi:10.5194/hess-9-139-2005, 2005.

Soulsby, C., Malcolm, R., Helliwell, R., Ferrier, R. C., and Jenkins, A.: Isotope hydrology of the Allt a' Mharcaidh catchment, Cairngorms, Scotland: implications for hydrological pathways and residence times, Hydrol. Process., 14, 747762, doi:10.1002/(SICI)1099-1085(200003)14:4<747::AIDHYP970>3.0.CO;2-0, 2000.

Soulsby, C., Tetzlaff, D., and Hrachowitz, M.: Are transit times useful process-based tools for flow prediction and classification in ungauged basins in montane regions?, Hydrol. Process., 24, 1685-1696, doi:10.1002/hyp.7578, 2010.

Speed, M., Tetzlaff, D., Soulsby, C., Hrachowitz, M., and Waldron, S.: Isotopic and geochemical tracers reveal similarities in transit times in contrasting mesoscale catchments, Hydrol. Process., 24, 1211-1224, doi:10.1002/hyp.7593, 2010.

Stewart, M. K., Morgenstern, U., and McDonnell, J. J.: Truncation of stream residence time: how the use of stable isotopes has skewed our concept of streamwater age and origin, Hydrol. Process., 24, 1646-1659, doi:10.1002/hyp.7576, 2010.

Timbe, E., Windhorst, D., Crespo, P., Frede, H.-G., Feyen, J., and Breuer, L.: Understanding uncertainties when inferring mean transit times of water trough tracer-based lumped-parameter models in Andean tropical montane cloud forest catchments, Hydrol. Earth Syst. Sci., 18, 1503-1523, doi:10.5194/hess-18-15032014, 2014. 
Vaché, K. B. and McDonnell, J. J.: A process-based rejectionist framework for evaluating catchment runoff model structure, Water Resour. Res., 42, W02409, doi:10.1029/2005WR004247, 2006.

Viville, D., Ladouche, B., and Bariac, T.: Isotope hydrological study of mean transit time in the granitic Strengbach catchment (Vosges massif, France): application of the FlowPC model with modified input function, Hydrol. Process., 20, 1737-1751, doi:10.1002/hyp.5950, 2006.

Weiler, M., McGlynn, B. L., McGuire, K. J., and McDonnell, J. J.: How does rainfall become runoff? A combined tracer and runoff transfer function approach, Water Resour. Res., 39, 1315, doi:10.1029/2003WR002331, 2003.
Wilcke, W., Yasin, S., Schmitt, A., Valarezo, C., and Zech, W.: Soils along the altitudinal transect and in catchments, in: Gradients in a Tropical Mountain Ecosystem of Ecuador, edited by: Beck, E., Bendix, J., Kottke, I., Makeschin, F., and Mosandl, R., Springer, Berlin, 75-85, 2008.

Windhorst, D., Waltz, T., Timbe, E., Frede, H.-G., and Breuer, L.: Impact of elevation and weather patterns on the isotopic composition of precipitation in a tropical montane rainforest, Hydrol. Earth Syst. Sci., 17, 409-419, doi:10.5194/hess-17-409-2013, 2013. 